\title{
La arquitectura de lo nuevo
}

The architecture of newness

WILLIAM BRINKMAN-CLARK*

México

*wbc@unam.mx

iD https://orcid.org/0000-0002-3163-6170

Artículo de investigación

Recepción: 28 de Abril de 2020

Aprobación: 10 de Junio de 2020

\section{Cómo citar este artículo:}

Brinkman-Clark, W. (2020). La arquitectura de lo nuevo. Designio. Investigación en diseño gráfico y estudios de la imagen, 2(2), pp. 87-113. Recuperado a partir de: http://cipres.san-

mateo.edu.co/index.php/designio

Reconocimiento-SinObraDerivada 4.0 Internacional (CC BY-NC-ND) 


\section{$88 \quad$ Resumen:}

En el ámbito de la arquitectura y el urbanismo, ¿qué significa proyectar algo nuevo? Este artículo problematiza el concepto de lo "nuevo" con base en la manera en que fue desplegado en las vanguardias artísticas europeas del siglo XX. Lo anterior, con el fin de analizar uno de los movimientos arquitectónicos más radicales de la historia occidental: el constructivismo ruso. La propuesta del artículo es que el ámbito de la arquitectura en especial resalta un problema "temporal" inherente al concepto de lo "nuevo" que no aparece en otros medios artísticos. La intención es que mediante el estudio del concepto de lo "nuevo" en el contexto del constructivismo, el lector pueda a su vez utilizar el marco histórico-conceptual presentado para asumir una postura crítica ante el ejercicio arquitectónico y urbanístico actual.

Palabras clave: Teoría de la arquitectura; constructivismo; Moisei Ginzburg; vanguardia; Revolución Rusa; condensador social.

\section{Abstract:}

In architecture and urbanism, what does it mean to produce something new? This article studies the concept of "new" based on the way this concept was used in the European avant-garde of the XX century. The author analyzes one of western history's most radical movement: Russian Constructivism. This article proposes that architectural practice sheds light on a temporal problem inherent to the concept of "newness" that is otherwise clouded in other artistic mediums. The thought is that, by studying the concept of "new" in the context of Russian Constructivism, the reader will be able to use the historical and conceptual framework presented to assume a critical posture towards contemporary architectural and urbanistic practices.

Keywords: Architectural theory; constructivism; Moisei Ginzburg; avant-garde;

Russian revolution; social condenser. 


\section{Introducción}

En el ámbito de la práctica arquitectónica contemporánea, cooptado casi por completo por la lógica del mercado, sustentar la intención de un proyecto en la búsqueda de lo "nuevo" fácilmente podría ser tachado como un mero lugar común. Sin embargo, la banalidad y frecuencia con la que se usa el concepto no debe ser causa para trivializarlo. La eficiencia con la que se despliega la noción de lo nuevo debe motivarnos a hacer una pausa y pensar con detenimiento qué es lo que convierte a la novedad en una herramienta tan bien afinada.

Aunque pensar sobre el concepto de lo "nuevo" en la arquitectura no tiene nada de nuevo", hacerlo requiere de ciertas acotaciones historiográficas y epistémicas. Como petición de principio, habría que considerar que en la arquitectura actual toda discusión sobre lo nuevo necesariamente estaría anclada en la evolución del concepto de autonomía que surgió con el romanticismo y se consolidó en el esteticismo de finales del XIX. Lo anterior, para luego ser opuesto por las vanguardias más radicales del XX, es decir, está anclada en la idea de que es posible un tipo de existencia estética ajena y liberada de las demandas y las limitaciones materiales del mundo.

Esta discusión, inaugurada en el sistema kantiano, presente en las Cartas sobre la educación estética del hombre de Schiller, y viva hasta las polémicas de las posvanguardias, no desaparece en el discurso posmoderno de la diferencia. Como bien lo nota Boris Groys (2005), desde la condición posmoderna es difícil escapar la creencia moderna en la existencia de un algo extra cultural que sustenta la constante creación y valorización de lo verdaderamente nuevo. ${ }^{2}$

\footnotetext{
1 La palabra "nuevo" deriva del latín novus, que refería a lo reciente, lo inusual o extraordinario. A su vez, derivó del griego véos, que refería a la juventud, lo joven y lo fresco.

2 Para Jacques Rancière (2005), la constante manifestación de una contradicción originaria es un elemento constitutivo de la aventura moderna de la autonomía del arte. Toda comunidad de lo sensible que se presuponga autónoma y emancipadora manifestaría necesariamente esta contradicción porque supone un intento de construcción de consenso y reconciliación que suspendería -en la práctica- la autonomía desde la cual se configuró. Una comunidad estética -y su promesa de emancipaciónsólo podría ser lograda mediante una heteronormativación de lo sensible (pp. 29-36). Es justamente dentro de este marco teórico constitutivo, propio del contexto de sociedades capitalistas modernas, que se vuelve difícil diferenciar el concepto de lo "nuevo", esto es, saber si la "novedad" aparece como posibilidad de singularidad o como herramienta totalitaria.
} 
Las materializaciones del concepto de lo nuevo en la arquitectura no sólo aportan un marco idóneo para su "visibilización"3, sino que permiten añadir un elemento a la discusión: la relación que se abre entre la noción de intención -en el ámbito de la producción artística de lo nuevo en este caso- y el entendimiento y experiencia moderno del tiempo (Deleuze, 2008). Este artículo se propone, entonces, ofrecer al lector una perspectiva sobre el concepto de lo "nuevo" que parte de la discusión vanguardista del término y sus contradicciones.

Sin embargo, avanza también una propuesta sobre las facetas espacio-temporales del concepto; mismas que en la producción del proyecto arquitectónico vanguardista -en específico en la noción general del proyecto constructivista- hacen visibles las paradojas y las aporías presentes en el concepto moderno de lo nuevo; mismas que fueron expuestas por teóricos posteriores a los movimientos de vanguardia, como Enzensberger, Bürger, y más recientemente Rancière, Groys, entre otros. La intención de presentar esta perspectiva es que pueda servir al lector como un punto de partida para la eventual problematización de la manera en que la banalidad del concepto de lo "nuevo" se presenta en la práctica contemporánea de la arquitectura como una herramienta del fundamentalismo de mercado.

\section{La categoría de lo "nuevo" en la arquitectura}

Aun en su sentido más general, la relación entre la categoría de lo nuevo ${ }^{4}$ y el ámbito de lo arquitectónico da pie a una pregunta que sigue vigente hoy, de gran relevancia

3 Tomo prestado el concepto del 'abrazo' entre lo "visible" y lo "enunciable" como condición para la constitución del "saber" de Foucault (2010); más específicamente, de la versión que Deleuze (2014) dicta en sus cursos sobre él.

4 ¿Qué significa pensar en lo "nuevo" como categoría? Para Hans Blumenberg (2011), antes que nada, significaría tratar la novedad como elemento fundamental de la realidad humana. Es necesario considerar que el concepto de lo nuevo no es sólo una construcción histórica, también refiere (o lo intenta) a una dimensión de la "realidad" humana, a la noción espacio-temporal de la "novedad" como sucesión y diferencia. En el caso de tratar de dar sentido a una práctica arquitectónica específica, el uso del concepto de lo nuevo como categoría también presenta ciertos problemas concretos; situación que se aumenta cuando la noción de lo nuevo es parte constitutiva del programa, como lo fue, por ejemplo, en la gran mayoría de los movimientos de vanguardia. Dicho lo anterior, se enfatiza en la siguiente acotación: en las páginas que continúan se problematizará la categoría de lo nuevo sólo en tanto finalidad o intención, a su vez, sólo en lo que la práctica arquitectónica refiere. Esta distinción es posible, en primer grado, a partir de la tipología histórica que permite caracterizar el desarrollo de la institución arte y de las diferencias teóricas de análisis propuesta por Bürger (2010). En resumen, la finalidad sería uno de tres (3) elementos -junto con la producción y la recepción- que constituyen una tipología histórica para la interpretación del objeto estético que permite presentar la asincronía histórica del desarrollo de una categoría estética en los diferentes elementos de interpretación. En lo que al análisis de obra refiere, la intención se diferencia de la descripción como herramientas teóricas de análisis (pp. 67-70). Mientras que la intención es un nivel que permite analizar los movimientos artísticos en 
para el campo: ¿cómo podemos, si es posible, proyectar lo "nuevo" desde la arquitectura? De dicha pregunta derivarían, en un nivel más particular, varias cuestiones de igual relevancia: ¿qué se entiende cuando hablamos de proyectar algo nuevo? y ¿qué problemas presenta lo nuevo para la práctica arquitectónica en diferentes momentos y modos de producción históricos? La propuesta es continuar esta línea argumentativa que desciende de lo general hacia lo particular, para eventualmente desembocar en el caso particular que gustaría utilizar para ejemplificar la problematización mencionada: ¿cómo se conceptuó y materializó la categoría de lo nuevo en la arquitectura constructivista? ${ }^{5}$

Entonces, desde los cuestionamientos que surgen en un nivel teórico más general: ¿qué es lo nuevo, como categoría estético-política? Ante la pregunta, Peter Bürger (2010) recalca la necesidad de historizar y notar que, en lo que al estudio de los movimientos de vanguardia respecta, la categoría de lo nuevo sufrió una transformación radical en su paso de ser una categoría propia de la institución arte burguesa (el esteticismo), a la manera en que fue apropiada por los movimientos artísticos de vanguardia.

Bürger también enfatiza que, como categoría propia del programa estético y político de la vanguardia, finalmente deviene insuficiente e inútil. ${ }^{6}$ ¿Por qué pierde su potencia, objetiva y descriptiva, la noción de lo nuevo en el seno de los mo-

tanto su programa y la manera en que este encaja, en relación con otros programas en el desarrollo histórico de la institución arte; la descripción permite establecer diferencias a partir de las formas producidas por diferentes movimientos artísticos (p. 119). En adelante optaré sólo por utilizar el término "intención" por dos (2) razones: la primera es que parece evidente que dentro de la sistematización teórica de Bürger la finalidad es subsumible dentro de la categoría de intención, pero no viceversa. La segunda razón tiene que ver con que la orientación de ambas, por así decirlo, es la proyección en la medida en que el proyecto sería la enunciabilidad que prima sobre la eventual visibilización de la forma; de manera que, en lo que a esto refiere, hacer una distinción entre intención y finalidad no es necesario. ${ }^{5}$ En el entendido de que la noción de lo nuevo se desarrolló como parte integral del movimiento ideológico-estéticosoviético másamplio, comúnmentellamado constructivismo ruso o constructivismosoviético.

6 Bürger (2010) construye su argumento a partir de su lectura de la teoría estética de Adorno. El autor será cuidadoso en notar que si bien Adorno entiende lo nuevo como una categoría estética propiamente moderna y burguesa; el teórico de Frankfurt omite hacer una historización de la categoría, reduciendo su propuesta sobre lo nuevo a su sentido en tanto inscrito dentro de la cultura de la mercancía. Bürger, por su lado, enfatizará la particularidad de la categoría estética moderna (Adorno) de lo nuevo por medio de una contraposición histórica ante tres (3) iteraciones anteriores de lo nuevo: (1) la "nueva canción" del Minnesänger cortesano, en la cual la novedad es entendida como la posibilidad de variación, pero siempre y cuando se dé dentro de los límites del género. (2) La nouveauté en la tragicomedia francesa, la novedad es entendida como los efectos de shock esperados por el público, que son parte de (y garantizados por) la estructura misma del género. (3) La desautomatización propuesta por los formalistas rusos, la novedad se entendía como la renovación necesaria de los procedimientos de una forma literaria una vez que se había automatizado. Así, la diferencia de estos tres (3) usos del concepto o categoría de lo nuevo (con la que Adorno propone caracterizar la modernidad) se vuelve más clara: la diferencia radica en el entendimiento de lo nuevo no como la posibilidad de transformación, sino como de ruptura radical con toda tradición. En palabras de Bürger (2010), "Ya no se niegan algunos procedimientos artísticos y principios estilísticos, aceptados hasta entonces, sino toda la 
vimientos vanguardistas? El problema principal radica en que lo nuevo (como categoría estético-vanguardista) propone la abolición total de la institución arte; esto es, la abolición del ámbito de lo estético como esfera completamente separada y autónoma del ámbito de la práctica cotidiana (Bürger, 2010, pp. 86-87).

El problema resulta irónico, la existencia de una institución arte autónoma era lo que permitía pensar en la posibilidad de lo nuevo como categoría estética, es decir, si anteriormente la identificación o la producción de la novedad derivaba de la transformación sucesiva de los procedimientos artísticos, o del sistema de representación-o inclusive de la mera conciencia de estos-; la abolición de la institución arte significaba la destrucción de aquellos referentes que permitirían distinguir lo nuevo, por un lado, como novedad históricamente necesaria, por el otro, de lo nuevo como simple moda o arbitrariedad.

Poco más de una década antes, Hans M. Enzenberger (1963) ya había notado que, a causa del triunfo del capitalismo, el arte no tenía otro camino más que el de entrar al mercado; además, la conciencia vanguardista sobre este hecho no era suficiente para evitar que el arte no tuviera otro ámbito de desarrollo más que el del mercado. Para Enzenberger, la aporía de la vanguardia residía en que su proyecto proclamaba la producción de un arte cuya novedad venía del rechazo de la autonomía burguesa y su integración en la praxis cotidiana en el marco de un contexto social en el que dicha cotidianidad estaba marcada, casi en su totalidad, por una red de valores burgueses que demandaban la producción de futuro "como si se tratase de un artículo de consumo" (Enzenberger, 1963, pp. 9-10). ${ }^{7}$

En el problema espacio-temporal, inherente a todo proyecto arquitectónico que busca lo nuevo, la aporía expuesta por Enzenberger y Bürger es de suma importancia. Parecería claro que la intención de los proyectos vanguardistas era, jus-

tradición del arte"(pp. 86-87). A partir de esta precisión de la categoría de Adorno, Bürger construirá suargumentosobrela inutilidad de la categoría de lo nuevo entanto a los movimientos devanguardiaserefiere. 7 Enzenberger había expuesto el problema práctico al que se enfrentaba toda materialización de la teoría vanguardista, mismo que Bürger recalcaría años más tarde: abolida la autonomía de la institución arte, surgiría cierta 'imposibilidad' de distinguir lo nuevo como herramienta para, y producto de, la superación histórica del arte autónomo burgués y diferenciarlo de lo nuevo como mera herramienta creadora de plusvalía; esto es: sería imposible distinguir la novedad emancipadora de lo nuevo en tanto producto de un sistema de dominación que conservaba y fortalecía la separación burguesa entre estética y práctica; entre vida y arte (Bürger, 2010, pp. 76-77). Por su parte, el trabajo de Groys (2005) trata de mostrar que dicha distinción era falsa desde un principio, y que la novedad en la modernidad siempre ha sido una cuestión de administración de la cultura. 
tamente, hacer inteligible un mundo cuya promesa era combatir la autoconservación del sistema de dominación en el que se encontraban y al que se enfrentaron, y cuya eventual materialización fuese la hipóstasis de dicha intención emancipatoria.

En Bürger (2010) parece haber un reconocimiento de que la problemática podía encontrarse desde el momento de enunciabilidad de los proyectos vanguardistas, presente en los textos mismos de los movimientos y en su postura ante el pasado, la tradición, y la institución arte. En estos términos, "iMuerte al arte!" exclamaba Alexei Gan en el manifiesto constructivista (Bann, 1974, p. 36); Marinetti proponía "destruir los museos, las bibliotecas, las academias de todo tipo" (citado en González, Calvoy Marchán, 2009, p. 143). Por último, Manifiesto Dada de 1918 dice "abolición de la memoria" (Tzara, 1918, p. 25).

Ante este conjunto de proclamas lapidarias, Bürger (2010) propone una importante distinción: para los movimientos de vanguardia, la muerte, destrucción y abolición de la institución arte no significaba su desaparición, sino su superación; lo que pretendían las vanguardias (por lo menos conceptualmente) era el traslado de los principios de la institución arte al ámbito de la praxis cotidiana. ${ }^{8}$

No obstante, ¿con base en qué puede Bürger afirmar que el lenguaje usado por las vanguardias apunta en realidad a una superación de la institución arte y no a su desaparición? El argumento del autor se fundamenta en la necesidad histórica de una institución arte autónoma, tal y como lo fue el esteticismo burgués; como condición de posibilidad para la creación de un nuevo mundo en el que la separación anterior entre la estética y la práctica es superada. Resulta en una nueva cotidianidad que, al incluir valores estéticos en la praxis cotidiana, no estuviera organizada solamente alrededor de fines racionales. Una nueva vida en la cual la praxis cotidiana era estética y el arte práctico (Bürger, 2010, pp. 67-73).9

Siguiendo en un nivel teórico-general, sin la necesidad de remitirse al caso particular de la arquitectura constructivista, se puede empezar a dilucidar la problemática

8 Bürger (2010) usa el término "superación" en su sentido hegeliano: "Los vanguardistas pretendían la superación del arte -una superación en sentido hegeliano-. Pues el arte no debería ser destruido, sino trasladado a la praxis cotidiana, donde se conservaría de otra forma [...] Solo un arte que, en el contenido de las obras, se distancie totalmente de la praxis cotidiana (deteriorada) de la sociedad existente puede ser el centro desde el cual se organice una nueva praxis cotidiana." (p. 71) 9 Bürger (2010) reconoce que esta propuesta encaja perfectamente con la que fue elaborada por Marcuse. En efecto, las propuestas vanguardistas negaron la autonomía del arte (pp. 76-77); reconocían la imposibilidad de la integración del arte a la praxis cotidiana organizada de acuerdo con fines racionales: valores estéticos como la humanidad, alegría, verdad y solidaridad eran, según Marcuse, necesidades imposibles de satisfacer en una praxis cotidiana burguesa organizada sobre la primacía racional del principio de competencia (pp. 67-71). La 
que presenta la relación entre el concepto moderno de temporalidad y el concepto vanguardista de lo nuevo. Como se evidenció con anterioridad, las vanguardias pretendían que la novedad que proponían (en tanto ruptura radical con toda tradición) se diferenciara por completo de la manera en que lo nuevo había sido entendido. Es decir, proponían una novedad que no fuera entendida como variación o diferencia, ni como inversión de las formas y los límites establecidos por la institución arte.

Sin embargo, si la finalidad de la vanguardia era la constitución de una nueva vida en la que los valores estéticos formaran parte integral de la praxis cotidiana, la única manera en la que esta intención podía ser enunciada y visibilizada era a partir de una propuesta de superación del pasado, de la institución arte como autónoma. Esto es, a partir del "reconocimiento" de la tradición (o del desarrollo histórico si se prefiere) de la institución arte como parte constitutiva no sólo de las condiciones materiales del presente $^{10}$, sino también de las condiciones de enunciabilidad y visibilidad -de los registros de comunicabilidad- del presente.

Todo lo expuesto hasta aquí no quiere decir que lo nuevo fuera una categoría "falsa", ni en su uso descriptivo - para hacer análisis de los movimientos de vanguardia-, ni en su uso productivo -como intención de los movimientos de vanguardia-. Como bien concluye Bürger (2010), el problema vanguardista de proponer una vida nueva (o de describir la vanguardia a partir de la novedad de sus productos) era que lo nuevo en tanto categoría es demasiado general: no permitía diferenciar la innovación de la moda, de la innovación históricamente necesaria.

Esta generalidad inevitablemente confina la categoría a la esfera de lo subjetivo; con ello hace de ella una categoría insuficiente en lo que al radicalismo propuesto por las vanguardias se refiere (Bürger, 2010, p. 90). A la conclusión de Bürger, el autor añade la

propuesta vanguardista no es, entonces, la de un arte comprometido socialmente (separado de la praxis pero que repercuta en ella), sino una superación del arte autónomo en la esfera misma de la práctica cotidiana. Con ello, la anulación de la separación del arte y de la vida. El arte comprometido socialmente, en tanto todavía separado de la práctica cotidiana, permitía el desplazamiento de las demandas sociales al ámbito de lo ideal, tal y como sucedía en la sociedad burguesa a la que se oponía la vanguardia, en la cual la separación entre la institución arte y la praxis permitían ubicar las imágenes de mundos nuevos, mundos mejores, en el ámbito del arte y no en el de la realidad (p. 71). 10 Ya sea negando, epistemológicamente, la posibilidad de una verdadera separación entre los ámbitos de la praxis y la estética; o reconociendo la separación junto con la noción de que, aun como esfera completamente separada, la esfera de lo estético afecta necesariamente, de una manera u otra, las condiciones materiales de existencia en tanto totalidad. 
paradoja temporal en la que incurre la categoría como intención del proyecto vanguardista: el proyecto de un futuro "nuevo" propuesto por las vanguardias se basa sobre la destrucción en el presente de toda la tradición estética que constituye el registro de visibilidad y enunciabilidad del pasado-presente que debe ser superado por la vanguardia.

Hasta aquí la conclusión es que la propuesta de destrucción es, en realidad, una de superación. Sin embargo, el futuro sólo puede ser nuevo como superación en tanto comparación con la tradición esteticista; asimismo, esa intención de novedad -el proyecto- solo es visible y enunciable si se construye a partir de los registros de inteligibilidad del presente. Bien nota Groys (2005) que uno de los principales problemas de todo proyecto utópico moderno es que solo es imaginable si aparece en el presente, como el negativo del pasado. Es decir, la utopía debe estructurarse de la misma manera que aquello que promueve destruir: si las vanguardias mostraban toda tradición como un engaño, destruirlas sólo tiene sentido si el futuro aparece como la verdad absoluta que se contraponía a dicho engaño.

Ambos proyectos, entonces, se estructuran de la misma manera-como promesas de verdad absoluta-, por lo tanto, son esencialmente conservadores e incapaces de producir lo nuevo. ${ }^{11}$ No fue gratuito que Foucault hiciera tan patente la oposición que la utopía presentaba su noción de heterotopía: "las utopías consuelan [...], se desarrollan en un espacio maravilloso y liso", a diferencia de las heterotopías que inquietan porque "impiden nombrar esto y aquello, porque rompen los nombres comunes o los enmarañan, porque arruinan de antemano la 'sintaxis'" (Bürger, 2010, pp. 11-12).

En un nivel más particular, Bürger (2010)cuestiona hasta quépuntolavanguardiarusa, a diferencia del resto de las vanguardias europeas, fue capaz de lograr la intención de los movimientos vanguardistas. Esta diferenciación de la vanguardia rusa con el resto de las vanguardias europeas tendría que ver, principalmente, con el hecho de que a diferencia de las sociedades europeas organizadas alrededor de un modo de producción capitalista-burgués, la vanguardia rusa se desarrolló en el contexto de un socialismo incipiente.

\footnotetext{
${ }^{11}$ En palabras de Groys"No es casual que ese utopismo [el de la modernidad] afirmara la labor destructiva de guerras y revoluciones [...] De ahí que las ideologías modernas hayan tomado siempre, desde el momento en que han alcanzado el poder, posiciones extremadamente conservadoras, como ocurría hasta hace relativamente poco en la antigua Unión Soviética. Ya se había alcanzado la verdad y, con esa victoria, la historia estaba consumada, así que ya no era posible otra novedad verdadera" (Groys, 2005, p. 33).
} 
La Revolución de Octubre había declarado (por lo menos en papel)12 nuevas condiciones sociales y materiales de existencia. Como se evidenciará más adelante, las im-

plicaciones conceptuales y temporales que la revolución (como acontecimiento) aportó a la vanguardia rusa hicieron de la naciente Unión Soviética un contexto estético-político históricamente singular. Dicha singularidad, evidente en la propuesta constructivista, ofreció alternativas interesantes al proyecto vanguardista de devolver el arte a la praxis cotidiana. Así, dentro del movimiento constructivista, la arquitectura resultó ser ejemplo de la potencia vanguardista y, a la vez, hipóstasis de sus contradicciones.

\section{La arquitectura y la vanguardia}

Si la intención de las vanguardias era la reconfiguración de la práctica cotidiana, ninguna otra disciplina tendría más potencial que la arquitectura. Sin embargo, la propuesta vanguardista de ir más allá de un mero "compromiso social" para lograr una nueva configuración de la vida (mediante la superación de la institución arte) difícilmente podría actuar como catalizador de novedad en el caso del medio arquitectónico. ¿Por qué? Lo que diferencia a la arquitectura como medio estético del resto de las artes sería, justamente, lo estrecho de su vínculo con las condiciones materiales de existencia de su época. ${ }^{13}$ Es un vínculo fundante que sólo

12 La naturaleza "programática" de la constitución soviética de 1918 -esto es, que es una constitución cuyo contenido se funda sobre ideales y derechos que deben ser materializados en el futuro; o lo que es decir que es la constitución que se sustenta y que regirá el nuevo mundo por venir- influye fuertemente en la noción de "realidad" y de "presente" que moldearon el proyecto del constructivismo ruso. En palabras de Joseba Buj (2017), la constitución soviética "describía una emergencia subjetiva en la arena de lo político y la consolidación de esa emergencia en un tiempo presente que irrumpe como porvenir, que es y no es, entonces, el tiempo en el que se consigna el documento (poseía un descolocado carácter programático: el porvenir revoluciona la inmanencia presente)".

13 En Estilo y época. El problema de la arquitectura moderna, el constructivista Mosei Ginsburg (1321) menciona que "lo que distingue esencialmente al arquitecto del escultor no es sólo la organización del espacio, sino también la construcción de su entorno de aislamiento. A partir de esto se desarrolla el método organizativo básico de los arquitectos, para quienes el mundo de la forma representa no tanto una serie de posibilidades ilimitadas e innumerables, sino simplemente un habilidoso intento de encontrar el justo equilibrio entre lo que es deseable y lo que es posible realizar; a fin de cuentas, resulta bastante natural que lo que es posible influya en el desarrollo del carácter mismo de lo que es deseable" (p. 117). 
se fortaleció por las condiciones socio-económicas que primaron en Europa y la mayoría de América hacia finales del siglo XIX y a lo largo de la mayoría del XX. ${ }^{14}$

Habría que considerar que los fundamentos de la arquitectura como medio surgen siempre de las condiciones materiales de existencia de su presente. De manera que si reconocemos, por un lado, este vínculo intrínseco entre la arquitectura y las necesidades del ser humano-tanto primarias como sociales-. Por otro lado, la intención vanguardista de crear una nueva vida -no para el pequeño segmento de la burguesía decimonónica afectado por el esteticismo, sino para la humanidad-. En este sentido, es posible concluir que, de acuerdo con la escala de la intención, la arquitectura moderna fue el medio "artístico" que presentó el mayor potencial y, a la vez, el mayor riesgo para atender al tamaño del programa radical que avanzaban las vanguardias. ${ }^{15}$

Potencial porque tenía la posibilidad de afectar directamente a la totalidad: burguesía, pueblo y elites (pensemos solamente en el alcance de los proyectos de espacio público durante el XIX); asimismo, riesgo pues dada la intensidad de incidencia que el proyecto arquitectónico de vanguardia se propuso tener sobre dicha totalidad, era más susceptible a ser categorizado como "imposible" a causa de lo que "la realidad" le oponía. El proyecto de arquitectura vanguardista fue fácilmente etiquetado como utópico en tanto irrealizable: un proyecto entusiasta ${ }^{16}$ por las limitaciones que le presentaron las condiciones materiales de existencia (como presente que se oponía a la posibilidad de realización del proyecto vanguardista) y la tradición (como pasado que era opuesto por el proyecto vanguardista).

14 Para un análisis minucioso sobre cómo los modos de producción capitalista del siglo XIX (imperantes en la mayoría de las sociedades occidentales) afectaron de modo particular al campo de la arquitectura: David Harvey Paris, capital de la modernidad (2008) y The Enigma of Capital (2010) 15 Si como lo nota Bürger (2010), la autonomía del arte propuesta por el esteticismo significa una separación del arte de la esfera de la praxis cotidiana, habría que preguntarnos si la arquitectura es capaz de erigirse como arte en dicho contexto particular. No es casualidad que la gran mayoría de los movimientos arquitectónicos del siglo XIX - desde las diferentes vertientes tardías del Neoclásico hasta el Jugendstil- fueran formalmente decorativos y que aun aquellos con intenciones de cambiar la esfera de la praxis social -por ejemplo, en el Arts and Crafts inglés-; básicamente proponían una estetización de la misma. En dicho contexto, pensar en la arquitectura como un arte autónomo, como "una arquitectura por la arquitectura misma" se vuelve problemático y contradictorio a la axiomática misma de la arquitectura, aquella que le permitiría distinguirse del resto en tanto arte. Por ejemplo, en el caso del problema de la percepción de las formas, M. Ginsburg (2007) notará específicamente que "el constructivismo se aleja completamente del concepto específico de percepción asociado a la vieja estética del siglo XIX, aún en el caso de grandes pensadores como Kant o Spencer. En ella la percepción estética se aislaba por completo de la finalidad del objeto percibido provocando la fatídica dualidad entre forma y contenido", y añadirá que el constructivismo "se plantea, considerando la percepción también como un factor material determinado, la tarea de organizar esa percepción [Énfasis agregado]" (p. 342). 16 Véase el concepto kantiano de entusiasmo en I. Kant (34) Antropología en el sentido pragmático, pp. $31-32,63,80,158$ y 176.) 
De cara ante este enigma, el constructivismo ruso resolvió no proponer utopías futuras que la constitución material del presente podría desechar como imposibles; más bien, contrario al proyecto arquitectónico vanguardista, propuso futuras heterotopías sustentadas sobre un presente fantástico. Es decir, en contra de la proyección utópica del presente (propia de los proyectos arquitectónicos vanguardistas) el constructivismo ruso propuso una arquitectura programática que imaginaba no sólo un nuevo futuro, sino un nuevo presente que servía de sustento de dicho futuro; propuso una totalidad visible en tanto "fantasía arquitectónica" . ${ }^{7}$

Por lo anterior, entre muchas otras cosas, en lo que a las vanguardias arquitectónicas refiere, el constructivismo ruso es un caso que debe ser analizado aparte. Además de adelantar una propuesta de un futuro que podría ser considerada de vanguardia, junto con ella propuso también una nueva realidad post revolucionaria y socialista. El constructivismo ruso no sólo propuso la posibilidad de un "futuro nuevo", sino que lo hizo montado sobre la propuesta de un "presente nuevo".

De tal manera, durante la década de 1920 el régimen soviético que emergió victorioso de la revolución se encontró ante la tarea hacer enunciable a la ideología sobre la cual se sustentaba su causa. Además, debía hacer visible tanto al futuro que dicha ideología prometía, como al presente revolucionario desde el cual se desplegaría. Si bien cabe mencionar que al interior del régimen tanto las estrategias como los métodos adelantados para lograr dicha visibilidad eran varios -frecuentemente opuestos entre sí (Hosking, 1992) -; había un consenso general de que la materialización de las promesas de la revolución era lo que se tenía que lograr. La arquitectura, entonces, apareció como una herramienta ideal para lograr dicho acometido; se les pidió a los arquitectos soviéticos imaginar y dar forma a algo nunca antes visto, que sólo existía como enunciado: "construir la realidad y la organización de las formas de la nueva vida" (Ginsburg, 2007, p. 337).

\section{El constructivismo ruso}

En la discusión que se emplazó sobre cómo debería ser una arquitectura que diera forma a ese futuro inédito, puede entreverse que uno de los problemas más profundos a los que se enfrentaría la arquitectura tenía menos que ver con forma y

\footnotetext{
17 Hay que entender la "fantasía" específicamente como era entendida por el constructivismo. D. Khmelnitsy (2013) recuerda que fantasear "es algo completamente pragmático que no tiene nada que ver con la creación de utopías o fantasías sociales románticas, sino con una manera profesional de identificar posibilidades de diseño que resolverán problemas específicos relacionados con el proyecto" (p. 20).
} 
función; más con la diferenciación conceptual necesaria entre el pasado y el futuro -entre lo viejo y lo nuevo- y la relación que tendría con el presente revolucionario.

Una de las grandes diferencias entre los constructivistas rusos y las vanguardias europeas fue, sin duda, que la (re)presentación de la realidad en que se pretendían desarrollar era radicalmente distinta. A saber, no solo era diferente el presente (en tanto condición material de existencia), también había una diferencia entre la manera en que conceptuó el tiempo presente en si..$^{18}$ Montados en la misión revolucionaria de crear un nuevo mundo y estableciendo la revolución como evento temporal de cesura, los artistas rusos voltearon hacía las vanguardias europeas en búsqueda de un lenguaje que sirviera para expresar lo que hasta ese momento era sólo el sueño de un futuro radical.

Dichas vanguardias, no eran aptas según el contexto histórico y material en el que se habían desarrollado -en algunos casos eran contradictorias- para representar el logro histórico singular que significaba la revolución rusa y la potencia transformadora que implicaba: "el joven país de los soviets" dice I. Korobina:

Al poseer recursos limitados, tenía la necesidad ingente de responder a los requerimientos de la época [...] La supresión de la propiedad privada de la tierra y los bienes inmuebles, así como la planeación estatal de la economía fueron un vector para el desarrollo de la construcción urbana. (Arroyo, 2015, p. 159)

En Constructivismo, Alexei Gan señalaba enfáticamente la importancia histórico-temporal de la revolución: "El constructivismo está avanzando [...] ha sido liberado por la revolución proletaria. Una nueva cronología comienza con el 25 de octubre, 1917" (Bann, 1974, p. 36).

Como Gan, muchos artistas soviéticos entendieron que antes de darse a la tarea de hacer visible el nuevo mundo, primero habría que llevar a cabo la formalización de

\footnotetext{
18 El constructivismo ruso debe considerarse vanguardia no sólo en la medida en que compartía características con el resto de las vanguardias europeas, sino también en la medida en que divergía considerablemente de ellas; de ahí su potencia vanguardista. Estas diferencias estaban del lado de una radicalización, y no de una contradicción, de la intención vanguardista, por lo que no creo deban ser consideradas como obstáculo en el establecimiento de una cierta fraternidad entre la vanguardia europea y el constructivismo ruso. Sin duda el constructivismo ruso puede considerarse como vanguardia en la medida que, mediante el llamado a la creación de un nuevo orden estético, se presentaba como una reacción a los valores del Romanticismo y del esteticismo, como lo era la noción de la individualidad como vitalidady espontaneidad (Arroyo, 2015, p. 148), y el rechazo a la injerencia del intelectualismo en la esfera del arte (Bann, 1974). La intención vanguardista de transformar la vida cotidiana, mediante su revalorización a partir de ideales estéticos, también prevalece en una gran parte de los escritos constructivistas, particularmente en los de Mayakovsky, Gan, y Ginsburg. Quizá fue en la Unión Soviética de la década de 1920, y no en los países europeos, dónde la intención vanguardista tuvo más oportunidad de materializarse .
} 
su proyecto. Lo anterior, en gran parte sustentado en una visión marxista de la realidad; en tanto presente, basado principalmente en la potencia estética de un nuevo entendimiento de la relación entre el valor de uso y el valor de cambio. Estos artistas comprendieron que antes había que enunciar una teoría y un proceso crítico que una vez formalizado actuaría como fuente, sustento y guía para toda producción estética.

Si las vanguardias europeas habían encontrado en el ámbito de la arquitectura uno de los medios más adecuados para el eventual logro de sus intenciones, el constructivismo vio en la reconceptuación de la arquitectura el medio perfecto para la creación de un nuevo orden estético que, a la vez, fuera catalizador y constituyente de un nuevo mundo. Bann (1974) resume la diferencia de la siguiente manera: "si el constructivismo internacional obedecía a un imperativo estético, el constructivismo ruso obedecía a un imperativo político y social" (p. xxxvi).

Cuando los movimientos arquitectónicos de vanguardia más cercanos al constructivismo -pensemos en el futurismo, el Neue Sachlichkeit, o De Stijl- se dieron a la tarea de crear un nuevo orden estético que repudiara el canon predominante en el ámbito estético burgués del cual derivarían las nuevas formas. Lo hicieron en el contexto de un presente que nunca abolió (por lo menos materialmente) la distinción de clases y el dominio de la burguesía. El constructivismo, sin embargo, se dio a la tarea no tanto de crear el nuevo orden estético, sino de crear todo un mundo nuevo -incluida la creación de un presente nuevo- y derivar de él un orden estético.

Según como se le vea, la tarea parece, o radicalmente innovadora, o ingenuamente tautológica. Quizá eran ambas. Como se ha reiterado, el problema era fundamentalmente temporal. Es decir, cuando Ginsburg (2007) nota que la misión de la arquitectura constructivista era construir la realidad ${ }^{19}$, lo que pone en crisis es la idea misma del proyecto arquitectónico. El entendimiento común del tiempo impide pensar en una "construcción de la realidad" en tanto esta es siempre presente. El proyecto arquitectónico es, por naturaleza, una intención de constituir un futuro diferente, por lo menos vis-a-vis el presente en el que se elabora la proyección. La pregunta para el constructivista se vuelve ¿cómo proyectar un presente nuevo? La respuesta, como se verá a continuación, tuvo que ver con un entendimiento del mundo natural y de sus leyes, basado en los principios de la dialéctica materialista. ${ }^{20}$

19 Por "construcción de la realidad" el autor hace referencia a la idea de una formación material del mundo presente que adquiere objetividad en su exterioridad, como algo opuesto a la "representación de la realidad" en tanto noción epistemológica moderna de la realidad como construcción subjetiva que adquiere su objetividad en tanto comunicable. 20 Para el concepto de dialéctica materialista, véase F. Engels (1961) Dialéctica de la naturalezay Anti-Dühring: la subversión de la ciencia por el señor Eugen Dühring (1981) y G. Lukács (1985) Historia y consciencia de clase. 
La solución no estuvo exenta de problemas y contradicciones; exponerlos y abrirlos a discusión es el propósito que hasta ahora ha tenido en mente este escrito. Se pretende realizar más tangible llevando ahora la discusión a un nivel más particular: un análisis de la enunciabilidad del proyecto constructivista a partir de los escritos de Moisei Ginzburg, quien tal vez fue su teórico más prolífico. Entre los artistas, en especial entre los arquitectos constructivistas, quizá fue Ginzburg quien entendió mejor la necesidad de una elaboración del proyecto arquitectónico constructivista en un nivel formal. Lo anterior, dedicando una gran parte de su trabajo a la búsqueda y elaboración de una teoría que sirviera como sustento para toda elaboración proyectiva y toda materialización constructivista. Y en sus escritos, justamente, es donde más explícitos se hacen los problemas temporales a los que se enfrentó la intención de imaginar el mundo nuevo soviético.

\section{El tiempo de Ginsburg}

Los primeros escritos de Ginzburg (2007) en la revista Arkhitectura tenían como objeto atender una pregunta que aparecía como vital para el constructivismo naciente: ¿cuál es la situación de una obra artística en su contexto histórico y local? En 1923 (año en el que se escriben estos primeros artículos) la visión vanguardista en Rusia estaba fuertemente influenciada por la revolución, significada en el sentido más estricto de la palabra como el acontecimiento que había logrado lo que ningún otro país europeo: cerrar el ciclo histórico de la revolución burguesa. De ahí que la revolución rusa fuera conceptuada, en estos primeros escritos, como una cesura en el tiempo que, a la vez que cerraba y dejaba atrás un ciclo anterior, era también el punto de partida hacía un futuro radicalmente diferente. Este futuro aparecía vaciado, en la medida que rompía por completo con todo pasado: un escenario de posibilidad pura e infinita.

Esta conceptuación del futuro aparece clara cuando Ginzburg (2007) anuncia que la revolución ha "convertido en un abismo abierto la división existente, ya desde hace mucho tiempo, entre lo pasado y lo moderno" (p. 14). ${ }^{21}$ Sin embargo, lo que la metáfora del abismo también anunciaba era que la inserción de la revolución inevitablemente produciría dos (2) "presentes" contradictorios como cesura en esta

21 La metáfora del abismo vuelve a aparecer en un artículo de 1926, donde Ginzburg (2007) afirma que la década que ha pasado desde el triunfo de la revolución "Es una pequeña grietecita en el tiempo. Pero la revolución, después de destruir los prejuicios estancados y los cánones anticuados, convirtió esa fisura en un abismo" (p. 245). 
noción de tiempo. A lo largo de las propuestas plasmadas en los escritos, el presente aparecerá en algunas ocasiones como cesura pura entre presente y pasado. En otras, como el punto de inicio y sustento de un futuro que aparece como nuevo sólo en la medida que niega por completo la totalidad de aquel pasado que la revolución vino a cerrar. Estos dos (2) "presentes" aparecen juntos en una conferencia que Ginzburg dictó a la Asociación de Arquitectos Modernos en 1928. En ella afirmó que:

Los constructivistas abordan el problema del objetivo [...], y establecen las premisas para un tipo de vivienda completamente nuevo, diferenciado del antiguo. Es decir, para nosotros el objetivo no es la realización de un encargo, como tal, sino una labor conjunta con el proletariado, la construcción de una nueva realidad y de un nuevo modo de vida que se presenta ante él. En este ejemplo de la construcción de viviendas para trabajadores contraponemos a la vivienda del pequeño burgués una vivienda comunitaria, tratando así de facilitar el desarrollo de la cultura socialista [énfasis agregado]. (Ginzburg, 2007, pp. 360-361)

Si lo anterior se lee a partir del concepto de lo nuevo hasta aquí desarrollado, un problema aparece en el carácter irreconciliable de estos dos (2) presentes, problema que recuerda a la contradicción enunciada por Rancière al principio de este escrito. De manera que, antes de entrar al problema de la aporía que se produjo entre las dos (2) posibilidades de entender el presente desde el que debía actuar el constructivismo, habría que ahondar más en cada una de ellas, para así poder hacer más claro el problema que presentaron al momento de formalización del constructivismo.

Por un lado, el constructivismo ruso se encontró ante una noción implícita del presente en las teorías de las vanguardias europeas. Como ya se discutió anteriormente, en ellas el proceso de creación radical, muy parecido a lo que se buscaba para el nuevo mundo soviético, se basaba en el olvido y la destrucción total del pasado. Esto significó para las vanguardias europeas (específicamente en tanto a la noción de presente refiere) que, en la medida en la que el pasado era la condición de posibilidad -material e ideológica- necesaria de todo entendimiento del presente, entonces el olvido o la destrucción del pasado era también olvido o destrucción del presente en tanto realidad. Es decir, para las vanguardias el presente como realidad estaba invariablemente 
ligado con el pasado, y cualquier intento de creación radical necesitaba deshacerse de ambos en la medida en que eran inseparables. Sobre el elemento temporal en el concepto y el proceso de las vanguardias europeas, Enzensberger (1963) escribía:

Y este proceso sigue una trayectoria unívoca; lo que permite distinguir entre vanguardia, grueso y retaguardia. Las obras no van todas "delante" por igual; y sus respectivas posiciones de ninguna manera se consideran indiferentes. [...] No se trata de comparar la producción actual con la pasada. La metáfora de la Avant-Garde, aun cuando no excluye la noción subalterna y torpe de que lo creado en el pasado ha caducado ipso facto, no puede ser reducida a un obtuso culto de lo más nuevo. Va implícito en ella el concepto de no-simultaneidad de lo simultáneo: el estar presentes, juntos, en cada instante del proceso, precursores y rezagados. Hay una contemporaneidad interior al margen de la exterior. El en Avant de la Avant-Garde quiere, en cierto modo, realizar el futuro en el presente, anticiparse a la marcha de la historia. [...] Nadie sabe qué es "delante", y menos que nadie quien ha llegado a un terreno ignoto. No hay forma de protegerse contra esta incertidumbre. Sólo puede meterse con el futuro el que esté pronto a pagar el precio del error. El Avant de Avant-Garde encierra una intrínseca contradicción: sólo puede establecerse a posteriori [énfasis agregado]. (pp. 7-11) ${ }^{22}$

El ejemplo de la vanguardia europea era, entonces, uno que el constructivismo soviético no podía imitar. Si bien la negación del pasado era algo que tenían en común, el constructivismo no podía darse el lujo de ignorar el presente-o en el mejor de los casos, anticiparse a la marcha de la historia, tal y como lo notaba Enzensberger- porque la revolución

22 Enzensberger (1963) continuará haciendo explícita la aporía que encierra el proceso mismo de las vanguardias. En el mismo escrito añade que "La marcha de las artes por la historia es concebida como un movimiento lineal, definido y abarcable, en el cual uno puede determinar su lugar. Se pasa por alto, en tal idea, que este movimiento va desde lo conocido hacia lo desconocido; y que, por lo tanto, sólo los rezagados pueden decir dónde están" (p. 11). 
le obligaba a atender sus condiciones histórico-materiales. ${ }^{23}$ El presente de la revolución triunfante era el punto de partida del nuevo mundo; ignorarlo, u oponerse a él en una simultaneidad no-simultánea sería voltear la cara a todo lo que la revolución misma había logrado, bajo la premisa de que sólo así podría pensarse un mundo radicalmente nuevo.

La segunda noción de presente, que aparecería como contradictoria a la de las vanguardias europeas, era la del clasicismo burgués: una suma de todas las corrientes artísticas que respetaban, mediante la imitación o la reinterpretación a los cánones artísticos de la tradición. La conceptuación del presente en el clasicismo es más cercana a la de un tiempo lineal básico, en el cual el futuro aparece como ligado con el pasado mediante el presente. Esto, aunado a una idea moderna/ilustrada del progreso, hacía del presente el momento de producción que abona a la edificación cultural acumulativa que representa la noción de pasado.

Para el constructivismo, la imposibilidad de seguir los métodos creativos del clasicismo burgués era obvia. Como la revolución era momento de cesura, de cierre de una época anterior, la posibilidad de creación de un mundo verdaderamente nuevo descansaba en la negación del pasado. El presente constructivista debía existir, entonces, como punto de partida vacío, espacio que debía ser llenado con el proyecto de un futuro soviético. La contradicción interna de dicha propuesta era, evidentemente, que la realidad material de aquel presente revolucionario era consecuencia de un pasado clasicista; aún más, dentro del mismo relato marxista, el pasado que se pretendía negar era de facto condición de posibilidad necesaria para dicho presente revolucionario.

En tanto conceptuales, estas contradicciones eran remontables en el ámbito de la literatura, la pintura, o de otras artes plásticas. Sin embargo, en lo que a la arquitectura refiere, la contradicción irremontable a la que se enfrentaba era la realidad misma: la construcción del mundo nuevo no se haría sobre un lienzo en blanco o sobre una tabula rasa, sino dentro de una realidad que no podía destruir toda memoria del pasado ni negar su vínculo material con el pasado clasicista.

Consciente de que ninguna de las dos (2) nociones de presente servían como fundamento para la construcción del mundo nuevo, para Ginzburg la tarea del constructivismo era resolver dicha contradicción. Quizá es la razón por la cual el constructivismo (por breve que haya sido su vida) fue una corriente de tal po-

\footnotetext{
${ }^{23}$ Ginzburg(2017)notaque"Enlaunión delarteconlasmanifestacionescotidianasydiarias delavida, ensu carácter prosaico, sehalla esaverdaderarealidad delarte, lanaturaleza concreta desulenguajeformal, que es capaz de salvarle, además del gran peligro que amenaza al arte moderno: su carácter abstracto"(p. 17).
} 
tencia que Rancière asegura que nada igual ha vuelto a ser visto. Cuando la petición de principio contradice a la realidad material del presente, se produce una antinomia que sólo puede ser resuelta, negativamente, por medio de una proyección que se sustente en una radicalidad absoluta y que, sin ceder su naturaleza fantástica, atienda a la realidad material más contingente. Quizá uno de los ejemplos más claros de esto fue el concepto de "condensadores sociales" de Ginzburg, cuya teoría y materialización se sustentaba en que el presente fantástico avanzado por su proyección se convertiría, mediante su construcción futura, en un presente real. ${ }^{24}$

Si bien no hay manera de saber si Ginzburg estaba (o no) consciente de que las relaciones que utilizaba de los conceptos de pasado y de futuro generaban contradicciones para el presente de la creación artística, de la oposición simple que existe entre la creación artística que se sustenta en el pasado para la generación de lo nuevo; lo hace en la negación total del pasado como condición necesaria para la creación de lo nuevo. Así, en su artículo "Estética de lo moderno" reafirma que en el mejor de los casos, en lo que al pasado y la tradición estilística se refiere, estos deben ser admirados y estudiados desinteresadamente para evitar entregarse a alguno de los dos (2) extremos que él veía se daban en el contexto del arte contemporáneo a la revolución: ya fuera la resurrección de un estilo histórico, o la "insensata y completa destrucción de todas las referencias, tal y como se hace ahora" (Ginzburg, 2007, p. 14).

A la vez, estaba consciente de que este estudio "desinteresado" del pasado casi nunca se daba; aquel que servía sólo como conocimiento y no como sustento o modelo del cual partir. Por tanto afirmaba que, dada la situación en la que escribía, la revolución había hecho que entre estos dos (2) extremos fuera preferible el segundo, es decir, que era preferible crear el mundo nuevo a partir de la destrucción del viejo.

La inutilidad de ambas corrientes vuelve a ser mencionada por Ginzburg en su artículo "Lo viejo y lo nuevo". Allí se planteó la existencia de un "espíritu del presente", ignorado por los dos (2) frentes opuestos de lo viejo y lo nuevo, descritos por Ginzburg (2007) de la siguiente manera:

\footnotetext{
${ }^{24}$ El ejemplo construido más famoso de los condensadores sociales de Ginzburg se dio en el edificio Narkomfin, construido en Moscú entre 1928 y 1930. Para el concepto de condensador social, véase Arquitectura y urbanismo soviético de los años veinte, de Anatole Kopp (1974). Si estos proyectos se entienden como imágenes, a través de la teoría de la medialidad de Emanuele Coccia, se abre la posibilidad de una exploración ontológica radical del diseño, que por cuestiones de extensión no puede ser abordada aquí.
} 
Unos valoran y respetan la herencia cultural del pasado, y son incapaces de escapar esa influencia ni siquiera al tratar los problemas puramente modernos del presente; permanecen esclavos de esa herencia y desean, a costa de lo que sea, verter el nuevo vino en viejas botas. Los otros, más jóvenes, intentan ávidamente reproducir el semblante, aun apenas desvelado, del arte futuro, y se apoyan en el desprecio y la negación de la cultura del pasado. (p. 21)

Otra vez, las referencias son al clasicismo burgués como una corriente que esclaviza, y a las vanguardias europeas como intentos de invención creadora que necesitan de la autonomía del creador. Esto es, de su desapego individual de la cultura en tanto realidad material para ser exitosas. De nuevo, Ginzburg (2007) afirmará que para los constructivistas tanto un frente como el otro les "parecen ajenos" (p. 21). La apuesta parecía estar hecha: el constructivismo proyectaría un futuro nuevo, mediante la conceptuación de un presente que, al mismo tiempo que reconocía las condiciones materiales actuales, negaba todo vínculo con el pasado.

En el caso específico de la arquitectura, la negación del pasado como condición de posibilidad necesaria para la creación de un mundo nuevo, se encuentra en los escritos de Ginzburg cuando aborda el problema de la derivación de la forma. Unavez eliminado el pasado como la potencia creadoray fuente de inspiración para la creación burguesa, restaba la pregunta ¿desde dónde debe surgir la forma moderna? En la respuesta a esta pregunta se aprecia, de manera más concreta, como se manifestó la contradicción temporal.

Si bien el imperativo de negar el pasado aparece, en tanto regla, como una necesidad formal, en sus primeros escritos -especialmente en "Lo viejo y lo nuevo" un escrito de 1923- Ginzburg trató de matizar la contundencia de la regla, postulando que no debía ser uno o el otro, ni destrucción ni resurrección, y buscó generar la posibilidad de un punto medio. Sin embargo, este "entre" debía servir como fuente para la creación de un mundo nuevo; era un presente que parecía estar en franca contradicción con la idea de la revolución como momento puro de cesura en el tiempo. En palabras de Ginzburg (2007), el nuevo estilo con el cual debe construirse el nuevo mundo (que representaría la ideología de la revolución) debía poseer todas las características de una estética autónoma. No obstante, a la vez esforzándose por revelar la verdadera fisionomía de la realidad presente como consecuencia del triunfo de la revolución. 
Entonces, el problema transitó sobre la manera en que se conceptuó dicho presente. Si la negación del pasado parecía requisito, en estos primeros escritos no podía darse; la manera en la que aparecía el pasado, en el presente, era lo que validaba la estética del futuro. Así, lo que se debía intentar era formular una noción del presente que se desprendiera de su pasado y, al hacerlo, actuase como cesura que sirviera de condición de posibilidad para la imaginación de un futuro. En este sentido, si bien no negaba ni destruía el pasado, sí cancelaba cualquier injerencia formal que pudiera tener en el presente o, por lo menos, en la construcción de un nuevo presente.

Los primeros bosquejos de una solución a la contradicción en Ginzburg se darán justamente a partir de describir la misión del presente revolucionario como la búsqueda del "espíritu del presente". Su constitución se basaba en la existencia de fuerzas, leyes y elementos inmutables de la vida; propuesta que aparecía cercana al materialismo dialéctico. Estosconceptospermitierona Ginzburgpensarenun presentequese podíavincularconel pasadoypodíaseguirsiendosustento parala proyección deunfuturo radicalmentenuevo.

Este presente se separaba del pasado en la medida en que era plusvalía, acumulación, ornamento y lujo. Sin embargo, permanecía vinculado al pasado a partir de las fuerzas inmutables que subyacían al modo de producción y a la sociedad burguesa. De la misma manera, este presente podía servir de base para un mundo nuevo dado que su único vínculo con el pasado eran estas mismas fuerzas, que ahora debían ser distribuidas y encausadas de una manera en la cual nunca había sido vista en la historia de la cultura occidental. Entonces, el presente aparecía como uno dilatado; cesura, pero a la vez momento que se extiende para vincularse como constante con el pasado, por un lado, y sustento para el futuro radical, por el otro.

\section{La forma del presente "nuevo" en la arquitectura de Ginzburg}

Para Ginzburg (2007), esta nueva realidad, que desplazaba a la antigua-histórica y que la relegaba al ámbito especializado de la crítica (historia) del arte; tenía que ver con la irrupción en el mundo de la máquina y con las condiciones formales 


\section{8}

-completamente nuevas- que demandaba y representaba con su forma. La máquina indicó al artista cuál era el camino que había que seguir para la creación de lo verdaderamente nuevo. Sobre la estética de la máquina, Ginzburg (2007) resaltaba:

Economía inteligente del material y la energía, precisión en el movimiento de sus elementos con una cohesión total entre ellos, única en cada caso; un lenguaje conciso en la decoración de dichos elementos; pureza y honestidad en la composición con un eje de movimiento mostrado con precisión: esta es la estética de la máquina moderna, en la que, naturalmente, se presentan muchos principios organizativos para la actividad del artista. (p. 16)

La máquina sirve como modelo para el "presente dilatado". Su forma se sigue de las fuerzas inmutables de la naturaleza; como tal, brinda a los arquitectos una ley que debe obedecerse para la creación del mundo nuevo. En los escritos de 1923, la manera en que el proceso de diseño y construcción de las máquinas deben obedecer fuerzas innegables, por tanto, negar todo capricho del artista que pudiese resultar en un lujo; aparece como una perfecta analogía a la visión marxista de la constitución social del nuevo mundo. Este debía ser constituido a partir de reglas y modelos racionales, con el beneficio social primando siempre sobre capricho del individuo. ${ }^{25}$

Sin embargo, este presente dilatado no parecía ser otra cosa más que una sutura apresurada a la ruptura teórica que se abría entre la necesidad revolucionaria de crear mundos (que se calificaran de nuevos). Además, a la manera en que las vanguardias europeas, así como sus iteraciones rusas prerrevolucionarias, habían generado modelos de futuro; si bien podrían calificarse como "nuevos", lo eran en la medida en que se despegaban por completo de las limitaciones de su presente material y cultural. Ginzburg no sabía que vendría de una arquitectura que siguiera las leyes de la máquina, pero veía en las construcciones industriales de Estados Unidos (diseñadas por ingenieros) el surgimiento de formas nunca antes vistas; asimismo, imaginaba la posibilidad de una arquitectura habitacional y social que resultara radical al seguir las mismas pautas.

25 "En la capacidad de dominar las aspiraciones propias y superarlas en los límites de lo posible para cada arte y cada material, en la capacidad de encontrar las fronteras exactas de cada idea, en este sometimiento del arte a unas leyes sensatas de la composición y la forma se halla la fuente inagotable, vigorosa y vivificante de las fuerzas creativas" (Ginzburg, 2007, p. 17). 
Conforme avanzó la década de 1920, el constructivismo ruso se fue separando cada vez más, por lo menos en lo que a la arquitectura refiere, del resto de las vanguardias europeas. Sin duda, en gran parte por las características materiales y sociales específicas de la Unión Soviética; entre más se afianzaban los ideales de la revolución, fueron incrementando su diferencia radical con el resto de Europa. Esto contribuyó a su conceptuación antinómica del presente. Quizá, esta nunca fue más clara que en unas breves líneas que escribió Ginzburg en "Nuestra realidad”, artículo de 1927, donde afirmaba que:

En muchos ámbitos de nuestra economía y nuestra cultura está creciendo con fuerza y vigor una NUEVA realidad. Paralelamente a esta nueva vida, en nuestros días está terminando de descomponerse el legado del pasado existente. Lo mismo ocurre con la arquitectura. Aparecen y se fortalecen nuevos métodos de trabajo, y una nueva arquitectura dictada por nuestra nueva realidad tiene cada vez una forma más clara. Pero aún existen los restos mortales del eclecticismo prerrevolucionario, manteniendo sus principios en muchas de las obras que se levantan hoy en nuestras ciudades. Ésta es la dialéctica de una vida que se reconstruye de nuevo. Ésta es nuestra realidad [énfasis agregado]. (p. 309)

En el concepto de presente, descrito por Ginzburg, coincidían dos realidades paralelas y en una no-simultaneidad de lo simultaneo (como diría Enzensberger). Aquella que continuaba dando forma a los principios burgueses aparecía como un presente que, en tanto estaba ligado con el pasado, se descomponía y gradualmente desaparecía. Además, la realidad del presente dilatado que se extendía de manera dialéctica y se vinculaba con un futuro que negaba por completo cualquier pasado. Esta nueva realidad hizo del constructivismo ruso un modelo de visibilidad del futuro radicalmente diferente al de cualquier vanguardia europea. ${ }^{26}$

En este, la nueva realidad del presente existía sólo como una proyección del futuro sustentada en una negación de la vieja realidad del presente; su materia-

26 Ginzburg (2007) enuncia la distinción a nivel esquemático y de modelo, a partir de las diferencias que emergen entre las necesidades capitalistas y las necesidades socialistas que dictarían el proyecto arquitectónico en "Éxitos de la arquitectura moderna" (p. 295). También hará un recuento interesante de las similitudes y diferencias entre las vanguardias europeas y el constructivismo en "El frente internacional de la arquitectura moderna" (pp. 255-266). 
lización pretendía confirmar, a posteriori, la transformación del presente viejo en uno nuevo. ${ }^{27}$ Lo radical de la propuesta constructivista fue que el proyecto que debía transformar al mundo concilió la petición revolucionaria de atender las necesidades de presente mediante la creación de uno fantástico, radicalmente diferente que el presente material. Sin embargo, en su eventual materialización pretendía garantizar una eventual concordancia entre el presente teórico y el futuro material, garantizando también la construcción del emplazamiento; serviría no sólo de escenario, también de fuerza para el encauce de la vida nueva del mundo nuevo.

\section{Conclusión}

El impacto de las ideas radicales del constructivismo en el ámbito arquitectónico fue potente pero fugaz. Hacia finales de la década de 1920 perdía adherentes en la esfera política, a la vez que el realismo soviético se afianzaba como la estética de la Unión Soviética. ${ }^{28}$ La nueva realidad que pretendió construir el constructivismo existió sólo como enunciabilidad; cuando logró cierta materialización sólo se dio en escalas menores, frecuentemente impulsadas por una minoría del régimen revolucionario.

Cabe mencionar que, si bien en una gran parte del territorio soviético las condiciones materiales permanecieron similares a aquellas que se vivieron durante la revolución (o antes de ella); del otro lado de las fronteras soviéticas la ideología radical expuesta por la revolución rusa aparecía como peligrosa en la medida en que amenazaba la forma burguesa de vida que dominaba a la mayoría de las sociedades europeas occidentales (Hosking, 1992).

Así, ante el riesgo de una disolución desde el interior del régimen revolucionario; aún más, ante el riesgo exterior que los estados europeos presentaban; la urgencia del momento histórico de la incipiente Unión Soviética, así como su lugar en el teatro europeo, condenó al radicalismo de la vanguardia a retomar su lugar como mero esteticismo, como un sueño relegado al ámbito del arte, ajeno a la vida cotidiana.

27 Si en esta tesitura uno lee enunciados, que a primera vista aparecen simples, como "la búsqueda del arquitecto, en su esencia, es una invención igual que cualquier otra, cuya finalidad es organizar y construir un objeto práctico concreto, dictado en el presente, pero útil también para el mañana", la radicalidad del constructivismo, comparado con el resto de las vanguardias arquitectónicas europeas, se vuelve clara y potente. Vid M. Ginzburg, "Nuevos métodos en el pensamiento arquitectónico" (2007, p. 247)

28 En 1932 Stalin declaró al realismo soviético el estilo artístico de la Unión Soviética. Para el régimen, cualquier intento de perseguir y lograr el sueño de las vanguardias rusas significaba ignorar la realidad del presente y poner en riesgo la posibilidad de cualquier futuro socialista, condenando a las obras constructivistas a un largo olvido histórico (Arroyo, 2015, p. 35). 
Sin embargo, lo que queda es un ejemplo que no debe ser ignorado. En tiempos actuales, en los que la arquitectura se ha resignado a ser la herramienta del fundamentalismo de mercado, lo que no aparece como posible se descarta inmediatamente. No cabe duda de que lo nuevo en el ámbito de la arquitectura contemporánea es un artículo de consumo, como lo temían Adorno, Enzensberger y Bürger. En este contexto, habría que recordar siempre la responsabilidad que en algún momento se le confió a la arquitectura: crear un mundo nuevo que en su realización fuera conducente a una vida nueva. Así, desde ese conocimiento hacer crítica de todo proyecto que simplemente hace posible la misión que el presente le otorga al arquitecto: hacer visible el mundo creado por economistas, financieros, desarrolladores y tecnócratas.

El mundo que enunciaron los constructivistas se sustentaba sobre el axioma de que la fantasía no debía estar relegada al ámbito de lo imposible, sino que debía ser la guía del presente. Para los constructivistas, lo nuevo como sueño de emancipación y autonomía, se proyecta en el futuro sustentado sobre una enunciación fantástica del presente. Por ello, nunca aparece como imposible, aparece como consecuencia racional del presente nuevo que los arquitectos habían construido. El constructivismo decidió proyectar ese presente; al hacerlo produjeron lo que bien podría ser la arquitectura más radical y optimista del siglo pasado.

\section{Referencias}

Aristóteles. (1995). Órganon. Madrid: Gredos.

Arroyo, S. (2015). Vanguardia rusa. El vértigo del futuro. México: Instituto Nacional de Bellas Artes.

Bann, S. (Ed.) (1974). The Tradition of Constructivism. Nueva York: The Viking Press.

Blumenberg, H. (2011). Descripción del ser humano. Buenos Aires: Fondo de Cultura Económica.

Buj, J. (2017). La Constitución Mexicana de 1917: ¿melancolía o desesperanza? Estudios críticos de la cultura. Recuperdado de www.estudioscriticosdelacultura.com/articulos/index/30 
Bürger, P. (2010). Teoría de la Vanguardia. Buenos Aires: Las Cuarenta.

Deleuze, G. (2008). Kant y el tiempo. Buenos Aires: Cactus.

Deleuze, G. (2014). El poder. Curso sobre Foucault. Buenos Aires: Cactus.

Engels, F. (1961). Dialéctica de la naturaleza. Barcelona: Grijalbo.

Engels, F. (1981). Anti-Dühring: la subversión de la ciencia por el señor Eugen Dühring. Barcelona: Grijalbo.

Enzensberger, H. (1963). Las aporías de la vanguardia. Revista Sur, (285).

Foucault, M. (2010). Las palabras y las cosas. México: Siglo XXI.

Ginzburg, M. (2007). Escritos. 1923-1930. Madrid: El Croquis.

González, A., Calvo, F., y Marchán, S. (2009). Escritos de arte de vanguardia 1900/1945. Madrid: Akal.

Groys, B. (2005). Sobre lo nuevo. Ensayo de una economía cultural. Valencia: Pre-Textos.

Harvey, D. (2008). Paris, capital de la modernidad. Madrid: Akal.

Harvey, D. (2010). The Enigma of Capital. Nueva York: Oxford University Press.

Horkheimer, M. y Adorno, T. (2009). Dialéctica de la Ilustración. Madrid: Trotta.

Hosking, G. (1992). The First Socialist Society. Cambridge: Harvard University Press.

Kant, I. (2009). Crítica de la razón pura. México: FCE/UAM/UNAM.

Kant, I. (2014). Antropología en el sentido pragmático. México: FCE/UAM/UNAM. 
Khmelnitsky, D. (2013). Yakov Chernikhov. Architectural Fantasies in Russian Constructivism. Berlín: DOM.

Kopp, A. (1974). Arquitectura y urbanismo soviéticos de los años veinte. Barcelona: Lumen.

Lukács, G. (1985). Historia y consciencia de clase. Madrid: Sarpe.

Rancière, J. (2005). Sobre políticas estéticas. Barcelona: Museu d'Art Contemporani, Servei de Publicacions de la Universitat Autónoma de Barcelona.

Schiller, F. (1990). Cartas sobre la educación estética del hombre. Barcelona: Anthropos/ Ministerio de Educación y Ciencia.

Tzara, R. (2013) Siete manifiestos Dada. México: Tusquets. 